\title{
Different presentations of vulvar malignant melanoma: Report of two cases
}

\section{Vulvar Malign Melanomun farklı prezentasyonları: İki olgunun sunumu}

\section{Hullya Ayık Aydlın ${ }^{1}$ Zeynep Bayramoğlu² ${ }^{2}$ Cumhur İbrahim Başsorgun², Tayup Simsek ${ }^{1}$}

\author{
${ }^{1}$ Department of Obstetrics and Gynecology, Division of Gynaecologic Oncological Surgery, Akdeniz University Medical Faculty, Antalya, Turkey \\ ${ }^{2}$ Department of Pathology, Akdeniz University Medical Faculty, Antalya, Turkey. \\ Corresponding author: Hülya Ay1k Aydın, MD, Department of Obstetrics and Gynecology, Akdeniz University Medical Faculty, 07059, Konyaalti, \\ Antalya, Turkey \\ E-mail: hulya_ayik@hotmail.com \\ Received/Accepted: September 21,2017 / March 01,2018
}

Conflict of interest: There is not a conflict of interest.

\section{SUMMARY}

Malignant melanoma (MM), an invasive and aggressive cancer of the skin, causes distressing mortality and morbidity than other cancers. Gynaecological tract primary melanomas include a class of disorders that develop from melanocytes existing in the epithelium of the genital mucosa. Melanoma affects mucosal sites (such as vulva) as well as cutaneous part of the skin. The vulva includes both cutaneous and mucosal skin, and involves clitoris, labia minora/majora, the mons pubis, and the openings of the urethra and vagina. Herein, we aimed to present two cases with two different extreme presentations of vulvar MM, and subsequent treatments we intended to perform.

Keywords: Malignant melanoma, vulva.

ÖZET

Derinin invaziv ve agresif kanseri olan malign melanoma diğer kanserlere göre daha fazla mortalite ve morbiditeye neden olmaktadır. Jinekolojik sistem primer melanomları, genital mukoza epitelindeki melanositlerden gelişen bir grup bozukluğu içermektedir. Melanom, cildin kutanöz kısmının yanısıra mukozal alanları (vulva gibi) da etkiler. Vulva hem kutanöz hem de mukozal cildi içerir; klitoris, labium minor/major, mons pubis ve üretra ve vajina açıklıklarını içermektedir. Burada biz, vulvar malign melanomun iki farklı uç prezentasyonlarını ve tedavilerini sunmayı amaçladık.

Anahtar sözcükler: Malign melanoma, vulva.

\section{INTRODUCTION}

Malignant melanoma (MM), an invasive and aggressive cancer of the skin, causes distressing mortality and morbidity than other cancers. Gynaecological tract primary melanomas include a class of disorders that develop from melanocytes existing in the epithelium of the genital mucosa. They are infrequent, reporting almost $1 \%$ of all melanomas ${ }^{1}$. Regardless of existing particularly infrequent in the cervix and the vagina, it is the second utmost communal vulvar malignancy ${ }^{2}$.
Vulvar melanoma has an incidence of less than 0.2 per 100000 women per year, is approximately $10 \%$ of cancer of the vulva, and is the most common melanoma of the gynaecological tract ${ }^{3}$.

Melanoma affects mucosal sites (such as vulva) as well as cutaneous part of the skin. The vulva includes both cutaneous and mucosal skin, and involves clitoris, labia minora/majora, the mons pubis, and the openings of the urethra and vagina. Squamous cell carcinoma of the vulva is the commonest vulvar malignancy followed by vulvar 
$\mathrm{MM}^{4}$. MM of the vulva has a particularly poor prognosis with 8 to $61 \%$ of 5 -year survival rates ${ }^{4}$. Although the area of the vulva is $1-2 \%$ of whole body, approximately $3-7 \%$ of the female melanomas involve the vulva ${ }^{3}$.

We aimed to present two cases with two different extreme presentations of vulvar MM, and subsequent treatments we intended to perform.

\section{CASE REPORT}

\section{Case 1}

An 81-year-old G9P4A5 postmenopausal female patient admitted to the outpatient clinic of gynecological oncology with vulvar pain, and a palpable mass appeared for two months on the vulvar region in December 2016 (Figure 1). Her medical history revealed Parkinson disease for five, and bullous pemphigoid disease for two years. On her gynecologic examination a fragile, painful pink-white colored mass primarily originated from the left labium minus, and invaded the lateral wall of the vagina which easily bled on palpation was detected. On the left inguinal region, a palpable and fixed nodule measuring nearly $2 \mathrm{~cm}$ was detected. Vulvar punch biopsy material was obtained for histological diagnosis. Histology of vulvar biopsy material was reported as consistent with MM. Immunohistochemical evaluation revealed positive staining with Melan A, and HMB-45, and the material did not stain with Synaptophysin, CD 56, Chromogranin, CK 5/6, CD 3, CD 20, CK 20, CK 7, CEA, and P 63. PET-CT examination performed for grading of the disease demonstrated multiple diffuse hypermetabolic nodular lesions in both lungs the biggest one being nearly $1 \mathrm{~cm}$ in diameter (SUVmax: 9.2, consistent with metastatic lesion). No evidence of brain metastasis was found in the PET-CT. In the liver, lesions consistent with diffuse multiple hypodense hypermetabolic metastases the biggest one localized at 8 ' and dome measuring nearly $4 \times 3 \mathrm{~cm}$ in both lobes were observed (SUVmax: 17.9). In the left inguinal region, hypermetabolic lymph nodes with central hypometabolic region consistent with necrosis the largest being $3 \mathrm{~cm}$ in diameter were observed (SUVmax: 12.1, consistent with metastases). A hypermetabolic mass lesion with soft tissue density on the vulvar area measuring nearly $4.2 \times 2.5 \mathrm{~cm}$, and extending superiorly up to posterolateral aspect of the vaginal wall was observed (SUVmax: 20.2, consistent with the primary tumor). The patient having a disease consistent with metastatic disease was consulted with medical oncology. BRAF mutation analysis was requested from the patient for target treatment. Tumoral tissue of the patient could not reveal BRAF gene mutation on Codon 464 , and 600 . The patient was started on weekly 80 $\mathrm{mg} / \mathrm{m} 2$ doses of carboplatin treatment. After the 2 . dose the patient complained of sudden onset of inability to walk, and visual impairment, then cerebral CT was requested from the patient who demonstrated a mass consistent with metastatic lesion on the left temporal region measuring nearly $23 \times 20 \mathrm{~mm}$. The patient whose general health state deteriorated was died 40 days after establishment of diagnosis.

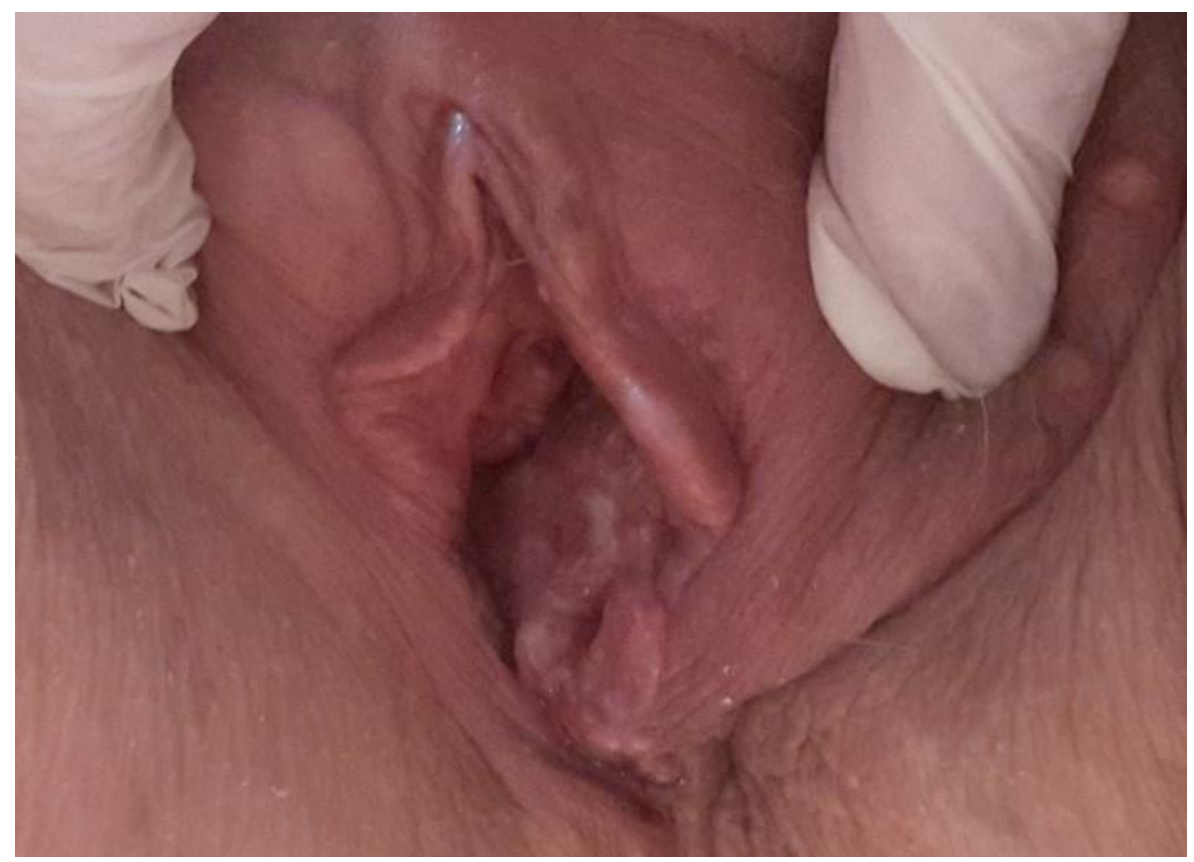

Figure 1. Vulvar mass 


\section{Case 2}

A 60-year old G2P2 patient admitted to the outpatient clinic of gynecologic oncology with a complaint of vulvar discoloration present for one year in December 2016 (Figure 2). She expressed that the discolored area enlarged, and darkened for the last six months. The patient had received adjuvant radiochemotherapy in the year 2010 with the indication of breast cancer. The patient was in remission under treatment with an aromatase inhibitor. Gynecological examination revealed a hyperpigmented macular lesion extending from right labium minor and major down to clitoris, and $1 / 3$ lower part of the vagina. The inguinal palpable lymph node was not detected. For histological diagnosis, histopathological examination of the vulvar biopsy material was reported as nodular type MM. Breslow thickness was reportedly 1.2 $\mathrm{cm}$, and V. Clark level. Satellite nodule was observed. Satellite nodule had an appearance of spindle cell. Tumor demonstrated a weak lymphocytic response. For immunohistochemical examinations, Melan A, HMB 45, histochemical melanin beaching methods were used.

Any metastatic foci were not detected on her CT. The patient underwent radical vulvectomy, partial vaginectomy, bilateral inguinofemoral lymph node dissection. Examination of the specimen did not reveal the presence of tumor at surgical margins (Figure 3A, B). However, the tumor was detected at the closest $3 \mathrm{~mm}$ away from the internal surgical margin. In tumor nodules, 8 mitoses $/ \mathrm{mm}^{2}$ were observed. A strong tumoral lymphocytic reaction was detected. Inguinofemoral lymph nodes were evaluated as reactive.

Multidisciplinary council assembled after surgery decided on examination for BRAF and C-kit mutation, and adjuvant chemotherapy and radiotherapy were planned for the patient with metastatic vulvar MM. The patient whose radiotherapy was planned after cisplatin and temozolomide treatment is in remission for six months.

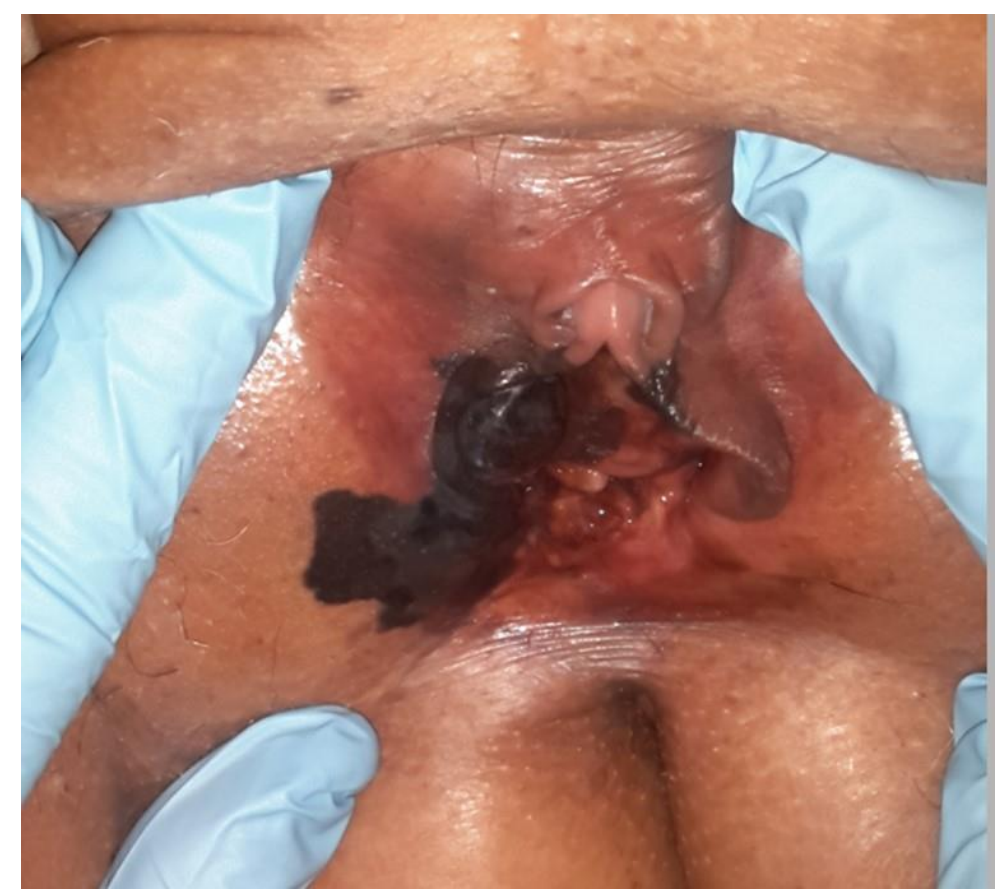

Figure 2: Vulvar discoloration 

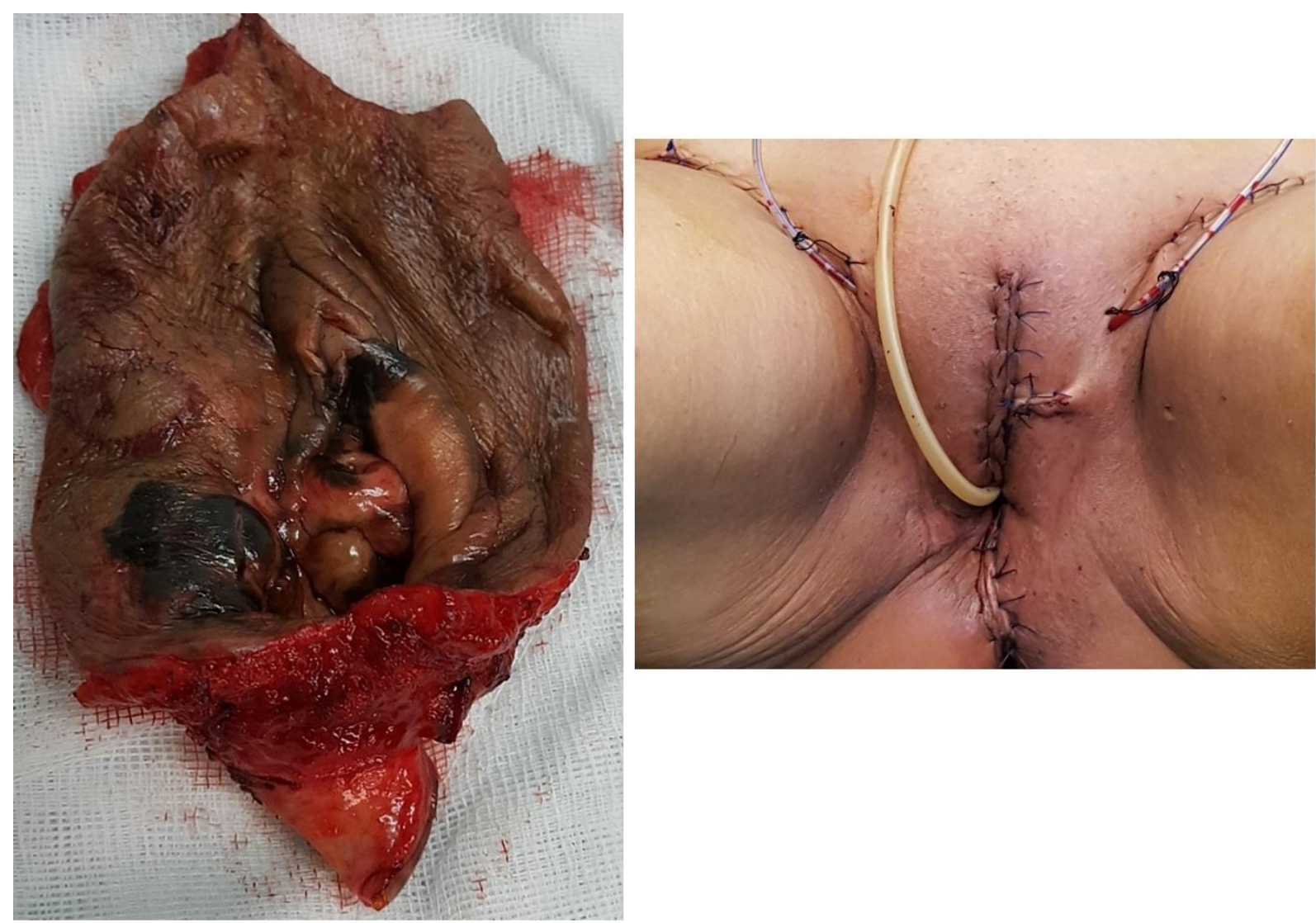

Figure 3 (a-b): a-) Vulvectomy specimen; b-) Postoperative appearance

\section{DISCUSSION}

The cutaneous melanomas are frequently observed amongst young ages in women, while the vaginal and vulvar melanomas are typically observed amongst older women. The vulva is an area where the examination and timely identification are tough. The cases visit the clinician too late and this delay affects the survival rate. The utmost characteristic signs from the vulva is stinging in the area or noticing a filling ${ }^{4}$. Our patients admitted with vulvar pain and a palpable mass in the first case and vulvar discoloration in the second case.

Substantial predictors of poor survival rate consist of increased Breslow thickness, increased mitotic rate, and ulceration. These features are altogether included in cutaneous melanoma AJCC Staging System $^{5}$. Nevertheless, the mentioned issues are not components of either the AJCC or FIGO systems for vulvar malignancy, which include depth of the tumor, width of the tumor, and its relation to neighboring structures ${ }^{6,7}$. AJCC and FIGO systems are established on information obtained from cases with vulval carcinoma and has not been confirmed in melanoma cases. It might be challenging to establish particular pathologic prognostic parameters for vulvar melanomas ${ }^{8}$.
Herein, in the second case, Breslow thickness was reportedly $1.2 \mathrm{~cm}$, and V. Clark level. Satellite nodule was observed.

Since vulvar MM is extremely uncommon, it is indeterminate which therapy is the finest 9 . Whether or not there are significant variances in the diagnostic, clinical, and prognostic characteristics and their utmost suitable management is at present unclear ${ }^{10}$. Surgery continues to be the basis of MM treatment, and vulvar MM is no exclusion. The type of surgery (radical vs. wide local excision) has not been shown to influence treatment outcomes for the MM of the vulva ${ }^{11}$. This is in harmony with the cutaneous MM outcomes, where clinical trial evidence has led to a gradual modification in surgical treatment suggestions from wide to narrower boundaries. Limited previous studies have revealed the pathologic margins and linked them to the outcomes ${ }^{12}$. If a wide surgical removal is achievable, it certainly suggests the best palliation and might accomplish treatment in some cases. Radiotherapy might offer effective palliation for inoperable tumors. SLN-positive patients and cases with distant metastasis ought to be handled on their merits, consistent with the general principles of the treatment of metastatic MM in 
SLNs and at distant sites, because there are no data to show that any distinctive treatment is likely to be more applicable for metastases from vulvar MM. In the present report, in our second case, the patient underwent radical vulvectomy, partial vaginectomy, bilateral inguinofemoral lymph node dissection.

Sentinel lymph node assessment has also been studied in MM of the vulva ${ }^{13}$. Though the detection of sentinel lymph node (SLN) is shown to be practical, a false negative rate of $15 \%$ has been also revealed ${ }^{14}$. In addition, it has been shown that the SLN technique itself might improve the risk of local recurrences ${ }^{13}$. SLN assessment in MM of the vulva is not the existing regular procedure universally and merits additional analysis with large clinical trials. In the present report, in our second case, although sentinel lymph node evaluation was not performed, inguinofemoral lymph nodes were evaluated as reactive.

Lately, substantially potent inhibitors of B-RAF and C-KIT oncogenic mutated proteins have displayed significant clinical efficiency in the management of metastatic MM cases whose tumors comprise activating mutations in these proteins ${ }^{14}$. CKIT mutations occur in about $18-35 \%$ of mucosal melanomas, including vulvar $\mathrm{MM}^{15}$. It is possible that treatments will be as efficient in treating metastatic vulvar MM with activating mutations as they are in treating melanomas arising in other locations.

\section{REFERENCES}

1. Bishop KD, Olszewski AJ. Epidemiology and survival outcomes of ocular and mucosal melanomas: A population-based analysis. Int J Cancer 2014; 134: 2961-71.

2. Sugiyama VE, Chan JK, Kapp DS. Management of melanomas of the female genital tract. Curr Opin Oncol 2008; 20: 5659.

3. Piura B. Management of primary melanoma of the female urogenital tract. Lancet Oncol 2008; 9: 973-81.

4. Sugiyama VE, Chan JK, Shin JY, Berek JS, Osann K, Kapp DS. Vulvar melanoma: a multivariable analysis of 644 patients. Obstet Gynecol 2007; 110: 296-301.
5. Balch CM, Gershenwald JE, Soong SJ, et al. Final version of 2009 AJCC melanoma staging and classification. J Clin Oncol 2009; 27: 6199-206.

6. Edge SB, Compton CC. The American Joint Committee on Cancer: the 7th edition of the AJCC cancer staging manual and the future of TNM. Ann Surg Oncol 2010; 17: 1471-4.

7. Pecorelli S. Revised FIGO staging for carcinoma of the vulva, cervix, and endometrium. Int J Gynaecol Obstet 2009; 105: 103-4.

8. Ross MI, HMA. Mucosal melanoma. In: Balch CM HCM, Sober AJ, Soong S, Atkins MB, Thompson JF, editors. Cutaneous melanoma. 5th ed. St. Louis: Quality Medical Publishing; 2009; Chapter 15.

9. Moxley KM, Fader AN, Rose PG, et al. Malignant melanoma of the vulva: an extension of cutaneous melanoma? Gynecol Oncol 2011; 122: 612-7.

10. Ragnarsson-Olding BK. Primary malignant melanoma of the vulva-an aggressive tumor for modeling the genesis of non-UV lightassociated melanomas. Acta Oncol 2004; 43: 421-35.

11. DeMatos P, Tyler D, Seigler HF. Mucosal melanoma of the female genitalia: a clinicopathologic study of forty-three cases at Duke University Medical Center. Surgery 1998; 124: 38-48.

12. Brand E, Fu YS, Lagasse LD, Berek JS. Vulvovaginal melanoma: report of seven cases and literature review. Gynecol Oncol 1989; 33: 54-60.

13. De Hullu JA, Hollema H, Hoekstra HJ, et al. Vulvar melanoma: is there a role for sentinel lymph node biopsy? Cancer 2002; 94: 486-91.

14. Busam KJ. Molecular pathology of melanocytic tumors. Sem Diagn Pathol 2013; 30: $362-74$.

15. Carvajal RD, Antonescu CR, Wolchok JD, et al. KIT as a therapeutic target in metastatic melanoma. JAMA 2011; 305: 2327-34. 